\title{
Michael E. DeBakey: A cardio-vascular surgeon whose innovations revolutionized the treatment of heart and blood
}

\author{
vessel
}

\author{
Md. Anisuzzaman* \\ Assistant Professor, Department of Cardiac Surgery, Chittagong Medical College, Chittagong, Bangladesh \\ *Corresponding author: Md. Anisuzzaman, Assistant Professor, Department of Cardiac Surgery, Chittagong Medical College, \\ Chittagong, Bangladesh
}

Received date: April 10, 2021; Accepted date: April 16, 2021; Published date: April 23, 2021

Citation: Md. Anisuzzaman, (2021). Michael E. DeBakey: A cardio-vascular surgeon whose innovations revolutionized the treatment of heart and blood vessel. J Thoracic Disease and Cardiothoracic Surgery, 2(1); DOI:10.31579/2693-2156/018

Copyright: (C) $2021 \mathrm{Md}$. Anisuzzaman, This is an open access article distributed under the Creative Commons Attribution License, which permits unrestricted use, distribution, and reproduction in any medium, provided the original work is properly cited.

\begin{abstract}
:
Michael Ellis DeBakey was a Lebanese-American cardiac surgeon and vascular surgeon, scientist and medical educator. After WW II, joined the faculty of Baylor University College of Medicine, serving as chairman of surgical department and hired surgeon Denton A. Cooley and revolutionized the management of cardiac and vascular diseases. His contributions in the development of roller pump for transfusion of blood directly from person to person which later became a component of the heart-lung machine. DeBakey's surgical innovations included coronary bypass operations, carotid endarterectomy, aortic aneurysm surgery, artificial hearts, ventricular assist devices, vascular grafts (Dacron) saved thousands of lives and made him surgical immortal.

Key words: DeBakey; heart surgeon; dacron; heart-lung machine; carcinoma; cardiothoracic surgery; encyclopedia Britannica; independent charter; myocardial infarction
\end{abstract}

\section{Early Life and Education:}

Michael DeBakey was born as Michel Dabaghi in Lake Charles, Louisiana on September 7, 1908, to the Lebanese parents Shaker Morris and Raheeja Dabaghi. The name was later anglicized to DeBakey [1,2]. His parents were Lebanese Maronite Christian immigrants, spoke French and fled to settle in Cajun Country where French was spoken. His father was a businessman involved in establishing rice farms, drug stores and estate agencies, and DeBakey helped out with keeping the books. He was inspired to become a doctor after meeting local physicians while he worked at his father's pharmacy [3].

DeBakey attended school in Lake Charles and was the eldest of five children, having three sisters and one brother, Ernest (Ernie), who would later become a thoracic surgeon. His sisters Lois and Selma also pursued careers in science. There was another sister, Selena [4].

As a child, DeBakey learned to play the saxophone and was taught by his seamstress mother to sew, crochet, knit and tat. He could sew his own shirt by the age of 10. He also became intrigued with the Encyclopedia Britannica and is said by colleagues to have read it from beginning to end. He learned French and German and participated in a Boy Scout troop. He won awards for vegetables he had grown in his garden [4].

\section{Tulane University:}

At Tulane University, DeBakey spent two years to complete his premedical course, gaining a BSc in 1929. A year earlier, he had already been granted admission to study medicine at Tulane University School of Medicine, where he also took up part-time work in surgical research [4].

During his final year in medical school at Tulane University, and prior to the establishment of blood banks, DeBakey adapted old pumps and rubber tubing and developed a version of the roller pump. He used the pump to transfuse blood directly and continuously from person to person, and this later became a component of the heart-lung machine. In 1932, DeBakey received an M.D. degree from Tulane University School of Medicine [4].

\section{Surgical training:}

Between 1933 and 1935, DeBakey remained in New Orleans to complete his internship and residency in surgery at charity hospital. And in 1935, he received a MS for his research on stomach ulcers. As was the trend for ambitious training surgeons at the time, and as his mentors Rudolph Matas and Alton Ochsner had done before him, DeBakey was encouraged to complete his surgical fellowships at the University of Strasbourg, france, under Professor Rene Leriche, and at the University of Heidelberg, Germany, under Professor Martin Kirschner from 1935 to 1937.

Returning to Tulane Medical School, DeBakey served on the surgical faculty from 1937 to 1948 .

DeBakey, who had mastered the ability to read both French and German before entering medical school, began translating French and German medical articles for his professors at Tulane. Many of these articles were provided from Dr Matas' personal foreign journal library. With his 
mentor, Alton Ochsner, in 1939 DeBakey postulated a strong link between smoking and carcinoma of the lung, a hypothesis that other researchers supported as well [4].

\section{WW II:}

During the WW II, DeBakey served in the U.S. Army as the director of the Surgical Consultants Division in the Surgeon General's office, Washington DC in 1942. In this role, he inspected field hospitals and performed surgery in Europe. He later had the rank of colonel in the Army Reserve. In 1945, he was given the Legion of Merit award. DeBakey helped develop Mobile Army Surgical Hospital (MASH) units, which stationed doctors closer to the front lines and improved the survival rate of wounded soldiers in the Korean War. DeBakey later helped establish the Veterans Administration Medical Center Hospital System and Research System. In an interview in 1998, Dr DeBakey also highlighted one of his greatest accomplishments initiated during his time in the Army Medical Corps: the conversion of the surgeon's General Library to the National Library of Medicine, which is under the direction of the National Institutes of Health [5].

\section{Surgical Career:}

After completing his service in the Army, Dr DeBakey returned to the faculty at Tulane for a short period before joining the faculty of Baylor University College of Medicine (now known as Baylor College of Medicine) in 1948, serving as chairman of the surgical department until 1993 (Figure 1).

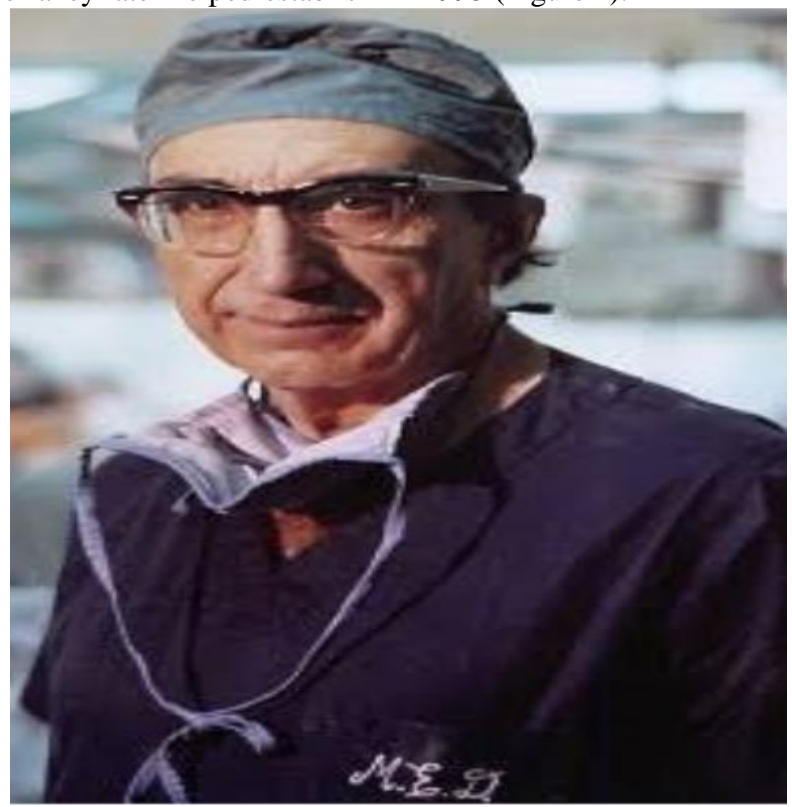

Figure 1: Dr DeBakey at Baylor University College of Medicine.

At his arrival, he noted that Baylor University College of Medicine had no teaching hospital, no surgical service, and no National Institute of Health (NIH) grants [6]. He quickly went to work and developed affiliations with the local Veterans Affairs and county hospitals. In 1968, he was appointed dean of the medical college and promptly separated the medical school from Baylor University, obtaining an independent charter from Texas for the Baylor College of Medicine. He served as president of the college of medicine from 1969 to 1979, chancellor from 1979 to 1996.

\section{Contributions to the field of Cardiothoracic Surgery:}

DeBakey made countless contributions to the field of medicine and surgery during his lengthy career. He developed the concept of the roller pump, while he was still a medical student at Tulane University. In his early years at Tulane University, he and Dr Ochsner together documented the rapid increase in primary pulmonary carcinoma in the early decades of $20^{\text {th }}$ century. Additionally, they published multiple reports on the options available for the surgical management of lung cancer and suggesting the correlation between tobacco smoking and primary pulmonary carcinoma [7].

Dr DeBakey made some of his greatest contributions to the field of cardiovascular surgery related to the surgical management of aortic aneurysms. He performed the first abdominal aortic aneurysm repair in the United States in 1952, only months after Dr Charles Dubost completed the first ever procedure in Paris. His first aneurysm repairs were completed with aortic homografts that DeBakey had harvested himself. He applied this similar knowledge and experience to perform the first thoracic aortic aneurysm repair in 1953 [8]. Dr DeBakey invented an alternative to homografts for conduits in his repair of aortic aneurysms. His original plan was to develop a conduit made of nylon; however, when he went to local departmental store to find nylon material from which to create his conduit, they did not have any in stock. The clerk suggested instead a new material called "Dacron," which Dr DeBakey used to create his first artificial grafts and is still the primary material used in aortic grafts today. Dr DeBakey initially created and sewed all his own Dacron grafts and even produced them for his colleagues until they become commercially available in the late 1950s [9].

In 1953, Dr DeBakey performed the first documented carotid endarterectomy on a patient who had reported symptoms of cerebrovascular insufficiency. He published 19 years' follow-up data showing the patient to be without cerebrovascular symptoms and providing evidence of persistent blood flow through the carotid artery. DeBakey also played major role in coronary revascularization in the early 1960s. He published his data of coronary revascularization with Dacron grafts in canines followed by first successful case of saphenous vein coronary artery bypass grafting in 1966 after a complication occurred during a coronary artery endarterectomy [10].

During the period, when heart transplant had become a popular alternative for those with advanced disease, Dr DeBakey pursued in the development 
of ventricular assist devices (VADs) and total artificial hearts (TAHs) as alternatives and bridges to cardiac transplantation. His initial success with VADs and disappointing results with TAH led him to abandon artificial heart research in favor of the VADs. ${ }^{9,11}$ Denton A. Cooley implanted a version of the total artificial heart in a patient at Baylor that led to one of the most renowned conflicts in the history of cardiovascular surgery between Drs DeBakey and Cooley. The dispute was resolved 4 decades later in 2007 when Dr DeBakey was accepted into the Denton A. Cooley Cardiovascular Society (Figure 2) [6].

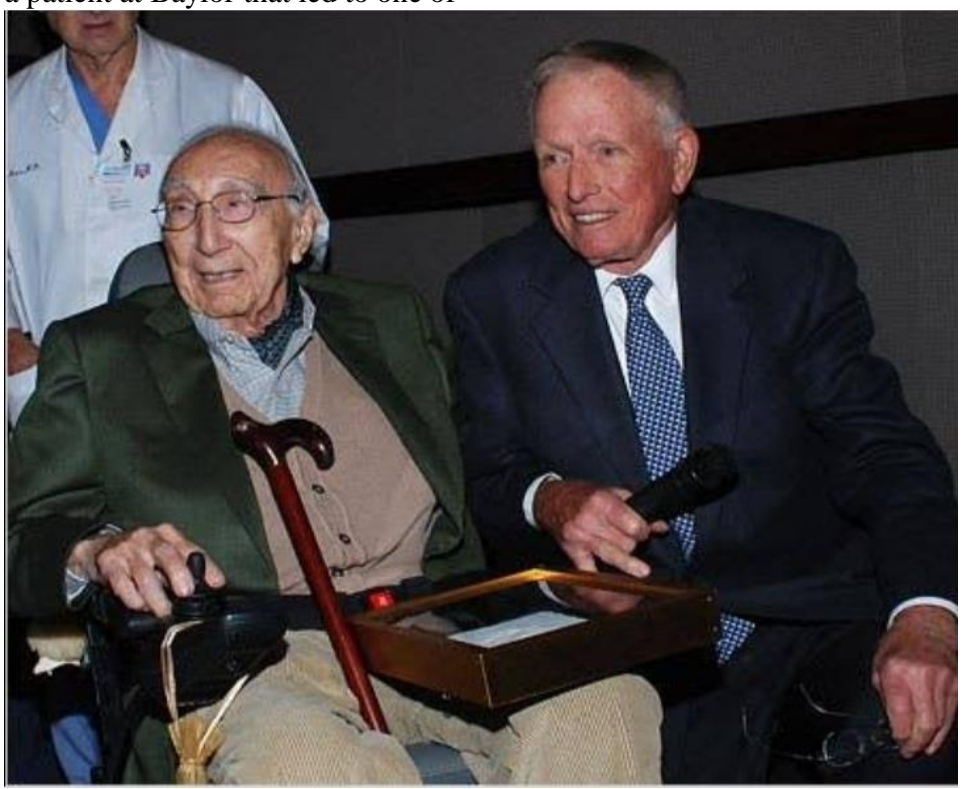

Figure 2: Dr DeBakey and Dr Cooley finally reconciled in 2007.

Dr DeBakey's continued research and collaboration with National Aeronautics and Space Administration engineers led to the development of an axial flow pump and eventually, to the MicroMed DeBakey VAD. Dr DeBakey considered one of his greatest contributions to the field of surgery to be the surgeons he trained during his lengthy career. Many residents consider Dr DeBakey as a demanding leader with zero tolerance. He instilled 2 principles in all his trainee; "attention to detail at all times" and "pursue excellence in all things" [12].

\section{Achievements and Awards:}

Dr DeBakey published more than 1400 medical articles and chapters of book and authored multiple books, including The Living Heart, The
Living Heart Diet, and The New Living Heart. In addition to being awarded the Legion of Merit in 1945, he received the Presidential Medal of Freedom with Distinction, the National Medal of Science, the Albert Lasker Award for Clinical Research, the Rodolph Matas Award in Vascular Surgery, the Rene Leriche Award, and the Congressional Gold Medal [13].

During the course of his career, he operated on many world leaders, including President Lyndon Johnson, President John F. Kennedy, President Richard Nixon, the Duke of Windsor, Russian President Boris Yeltsin (Figure 3), the shah of Iran, King Leopold of Belgium, and King Hussein of Jordan.

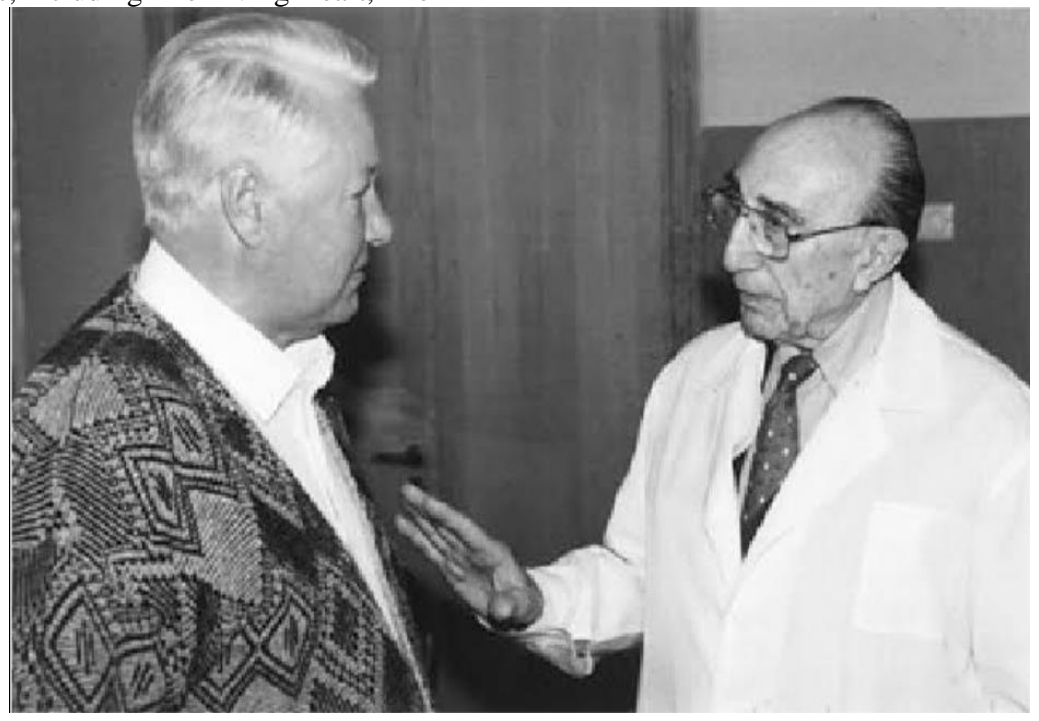

Figure 3: Dr. DeBakey and Russian President Boris Yeltsin in 1996. 
In addition to his participation and leadership of many medical associations, he served on the medical advisory committee of the Hoover Commission; the President's Commission of Heart Disease, Cancer, and Stroke during the Johnson Administration; 3 terms on the National Heart, Lung, and blood Advisory Council of the National Institutes of Health; and 2 terms as chairman of the Board of Regents of the National Library of Medicine. He has multiple institutes bearing his name, including the Michael E. DeBakey Veterans Affairs Medical Center in Houston, Methodist DeBakey Heart \& Vascular Center, and DeBakey High School for Health Professions in Houston, Texas, and Doha, Qatar [14].

\section{Personal life:}

Many considered him to be a workaholic, to which DeBakey responded, "I may be considered a workaholic, but I enjoyed it. The work was part of the joy of life. And there is nothing I enjoyed more than taking care of patients." The value of hard work and dedication instilled in him by his parents from a young age, and Dr DeBakey also cared very dearly for his family and heritage. He worked closely with his siblings during the course of his career. His brother Ernest was a thoracic surgeon in Alabama, and his sisters, Selma and Lois, were professors at Baylor College of Medicine [15]. His first wife Diana Cooper died from myocardial infarction in 1972. He married his second wife Katrin Fehlhaber DeBakey in 1975. He had 5 children-Ernest, Barry, Michael, Denis, and Olga. In January 2006, at age 97, Dr DeBakey was hospitalized for chest pain which on evaluation was found to be due to an ascending aortic dissection. After much debate, he eventually underwent surgical repair, a surgery he had helped pioneer decades earlier. After months of recovery, DeBakey was released from the hospital in good health. On July 11, 2008, Dr DeBakey died of natural causes at the Methodist Hospital in Houston, Texas [15].

\section{References:}

1. Caroline Richmond (14 July 2008). "Michael DeBakey: Cardiovascular surgeon whose innovations revolutionized the treatment of heart patients". The Independent.
2. Patricia Sullivan (13 July 2008). "Michael DeBakey- cardiac surgery pioneer who saved thousands in his 70-year career. San Francisco Chronicle. Retrived 29 November 2020.

3. Altman, Lawrence K. (13 July 2008). Michael DeBakey, Rebuilder of Hearts, Dies at 99. The New York Times. Retrived 4 December 2020.

4. "The Michael E. DeBakey Papers: Biographical Information. Profiles.nlm.nih.gov. Retrived 27 February 2019.

5. Gotto, Antonio M. (11 April 1991). "Profiles in Cardiology; Michael DeBakey”. Clinical Cardiology. 14(12): 1007-1010.

6. Cooley D A. In Memoriam: Michael E. DeBakey, 1908-2008. Tex Heart Inst J. 2008; 35(3): 233-234.

7. Ochsner A, DeBakey M. Primary pulmonary malignancy: analysis of 79 collected cases and presentation of 7 personal cases. Surg Gynecol Obstet. 1939; 68: 435-451.

8. DeBakey M, Cooley D. Successful resection of aneurysm of thoracic aorta and replacement by graft. JAMA. 1953; 152: 673-676.

9. Stoney W. Pioneers of Cardiac Surgery. $1^{\text {st }}$ ed. Vanderbilt University Press, Nashville, TN2008: 148-158.

10. Garret HE, Dennis EW, DeBakey ME. Aortocoronary bypass with saphenous vein graft. JAMA. 1973; 223: 792-794.

11. Kennedy JH, DeBakey ME, Akers WW, Ross JN, O'Bannon W, Baker LE, et al. Development of an orthotopic cardiac prosthesis. J Thorac Cardiovasc Surg. 1973; 65: 673-683.

12. Mattox K. Michael DeBakey: the consummate leader. Methodist DeBakey Cardiovasc J. 2009; 5: 32-36.

13. McCollum CH. The Distinguished Service Award Medal for the Society of Vascular Surgery, 1999: Michael Ellis DeBakey, MD. J of Vasc Surg. 2000; 31: 406-409.

14. Gotto A. Tribute to Dr. Michael E. DeBakey. Methodist DeBakey Cardiovasc J. 2010; 6: 61-62.

15. Salem P. Michael DeBakey: the real man behind the genius. Methodist DeBakey Cardiovasc J. 2010; 6: 42-44. 